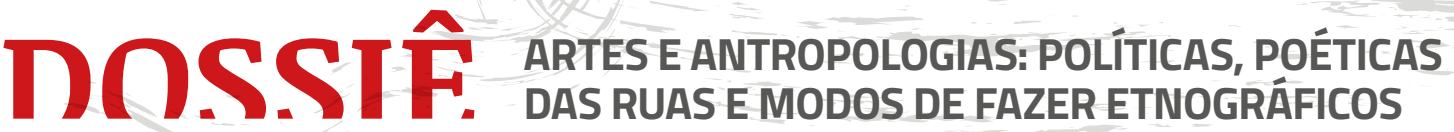 DAS RUAS E MODOS DE FAZER ETNOGRÁFICOS
}

DOI

https://dx.doi.org/10.11606/ issn.2525-3123.gis.2019.162819

ORCID

https://orcid.org/0000-0003-0857-9785

ORCID

https://orcid.org/0000-0001-8299-6830

\section{SOBRE MODOS DE FAZER ETNOGRAFIA E MODOS DE FAZER MUNDOS}

\section{PAULO RAPOSO}

Instituto Universitário de Lisboa (ISCTE-IUL), Lisboa, Portugal, 1649-026 - secretariado.ecsh@iscte.pt

\section{VITOR GRUNVALD}

Universidade Federal do Rio Grande do Sul (UFRGS),

Porto Alegre, RS, Brasil, 91509-900 - deptoas@urfrgs.br

Na organização desse dossiê (per)seguimos um itinerário que, há longa data, vem nos ocupando e está ligado, por um lado, aos cruzamentos entre arte e política e, por outro, à imbricação entre práticas e modos de fazer etnográficos e artísticos. Junto com outra antropóloga e fazedora de artes do corpo, Julia Ruiz di Giovanni, aqui ausente, mas sempre presente num diálogo que mantemos nos últimos anos, fomos potencializar essa troca que se deu tanto em momentos de discussão acadêmica, com congressos, seminários e cursos ou em eventos de caráter híbrido, com artistas e pesquisadoras, para não mencionar as conversas menos formais que vem atravessando o oceano Atlântico inúmeras vezes.

A questão que nos foi unindo se prendeu à possibilidade de pensarmos modalidades instigantes e inquietantes de entrelaçamento entre práticas artísticas, antropologia e ativismo político. Somos todas antropólogas com preocupações e compromissos sociais e políticos na prática disciplinar e todas, de alguma forma, conectadas com universos artísticos ou estéticos.

Esse dossiê almeja ser mais um contributo para as referidas discussões e campos problemáticos, num momento em que a produção de conhecimento acadêmico tem sido amplamente debatida dada a sua dificuldade de incorporação e de diálogo com outros saberes. 
A esse propósito, as práticas artísticas e os modos estéticos de pensar e agir sobre o mundo são, sem sombra dúvida, lugares de efervescência e de insurgência que, apesar de todos os bloqueios interdisciplinares, permeiam e ganham espaço no debate científico.

o pungente artigo de Daniela Feriani, ao tecer e destecer fios que nos conduzem pelos caminhos de sua etnografia assombrada sobre a doença de Alzheimer e processos demenciais, utiliza nomes, rostos, cenas e imagens para nos mostrar, parafraseando a autora, a potência da dissolução e a articulação de novas de formas de ver e narrar a experiência, muitas vezes borrada, de algumas possibilidades de vida.

Fabiana Bruno nos apresenta o resultado do que chama de "pacto de dupla indagação". Avança e se debruça, deliciosamente, sobre o então adormecido arquivo fotográfico de Etienne Samain sobre os índios Kamayurá e, no percurso, desvenda - o verbo não é aleatório - com imagens e silêncios eloquentes, instigantes heurísticas, processos e metodologias visuais experimentais.

Experimentações são também realizadas, de distintas formas, por Heléna Elias e Francesca De Luca e por Carolina Maia. No primeiro caso, são textos e imagens que buscam dar conta de um possível modo de descrever uma instalação site-specific, ATLAS: MATRIX, no Jardim Tropical de Belém, em Lisboa. Um dispositivo aberto que cruzava a pesquisa etnográfica de Francesca De Luca sobre práticas de nascimento e um conjunto de obras de cerâmica da artista plástica Heléna Elias e que reclamava ulterior colaboração, permitindo aos espectadores jogar e intervir com os elementos gerando, assim, também uma reflexão sobre processos de comportamento artístico colaborativo.

Já Carolina Maia experimenta, brinca com a linguagem epistolar e, na seriedade de uma brincadeira, para usar a famosa expressão de Victor Turner (play), mistura devaneios conceituais, políticos e pessoais que, ancorados na ancestralidade de autoras como Adrienne Rich e Gloria Anzaldúa, nos trazem, com enfoque deliciosamente desafiante, casos e descasos da constituição de uma política através da escrevivência lésbica, ainda que esse conceito de Conceição Evaristo não seja, no texto, acionado.

A seguir, temos o texto de Eduardo Faria Santos que retoma a discussão sobre movimentos sociais LGBT para, através de uma etnografia sobre o coletivo Revolta da Lâmpada, do qual um dos organizadores do dossiê faz parte, pensar novas maneiras a partir das quais arte e ativismo têm se entrelaçado em uma perspectiva que se quer horizontal, descentrada e interseccional e que coloca no afetivo e no "corpo livre" cernes de sua atuação política. 
Mariana Gonçalves, por sua vez, nos revela uma produtora de cinema amador, Cineground, fundada em Portugal após a revolução de 25 de Abril 1974. Autoras tanto das discussões sobre gênero e sexualidade quanto da antropologia visual aparecem na análise que, corroborando o que pensavam o artista plástico Óscar Alves e o cineasta João Paulo Ferreira, seus fundadores, mostra o caráter nomeadamente revolucionário dessa produção fílmica ao trazer para suas películas de Super-8 temáticas sexo-gênero dissidentes ainda criminalizadas naquele momento.

Filmes - ou, mais propriamente, filmações e representações - são também o material que analisa Pâmilla Vilas Boas Costa Ribeiro. Mas a autora, diversamente, estabelece um frutífero diálogo com a antropologia da performance para elucidar como se imbricam, de diversas maneiras, drama estético, social e ritual na produção de um filme com o batuque de Ponto Chique e outros grupos de batuques vizinhos ligados pelo rio São Francisco.

Encerrando a parte textual de nosso dossiê, temos o artigo de Luis Junior Saraiva e Pedro Olaia que, ao discutir uma performance drag e interativa realizada pelo último em três momentos, trata de experimentar e discutir, em uma encruzilhada transdisciplinar onde a teoria dialoga com a prática em interações extra-muros acadêmicos, a necessidade da experimentação que perpassa tanto campos disciplinares (arte, antropologia, performance, teoria queer) e linguagens (autoetnografia, imagens) quanto possibilidades outras de habitar e viver a experiência de gênero.

Nas contribuições à nossa seção Gestos, imagens $e$ sons, o caráter (auto) biográfico, mesclado à discussão teórico-conceitual, é também trazido à tona na curta contribuição de Marcia Vaitsman que se hiperliga em ligações a outros ensaios visuais da artista-pesquisadora. Partindo da investigação sobre uma "possível ética-estética da estrangeiridade, do trânsito e da impermanência", indaga, entre delírios, sutras e imagens, listas de artista que não são nunca somente listas.

Enquanto Otávio Raposo, em filme, nos conduz pelo universo de imagens e sons produzidos por $b$-boys e $b$-girls na cena breakbeat, vemos corpos em movimento, rodas, palmas e dinâmicas de deslocamento que a câmera acompanha em tomadas de vista não usuais e que são inseparáveis de música e som na constituição de processos de resistência nos quais batalhas artísticas, na medida mesmo em que, jocosamente, travam confrontos simbólicos, afirmam, igualmente, lugares existências próprios com códigos, estéticas e posturas singulares.

Na seção TER, por fim, o dossiê apresenta duas contribuições relacionadas às questões com as quais o antropólogo Arnd Schneider tem trabalhado. Trata-se tanto de uma resenha de seu último livro, Alternative 
Art and anthropology: Global Encounters, quanto de uma entrevista realizada por Rose Satiko Hikiji Gitirana e Jasper Chalcraft. Em ambas, é latente a zona de colaboração e fronteira entre arte e antropologia e a exploração mútua de campos de cruzamento e práticas compartilhadas.

Deste modo, no dossiê, entre textos e imagens que reclamam reflexão e experimentalismo nos modos de "fazer etnografia" e cruzam diversas modalidades e práticas oriundas do campo artístico e acadêmico, enfatiza-se o debate e diálogo entre categorias, conceitos, olhares ou formas poéticas e políticas de "fazer mundos".

A artista cubana Tania Burguera, uma das responsáveis pela cunhagem do termo arte útil, propunha não apenas um novo uso para a arte, mas que justamente ela fosse capaz de restabelecer a estética como um sistema de transformações (sociais, políticas, económicas, culturais). Muitos dos contextos aqui analisados por olhares antropológicos e artísticos plurais e em graus de formação e maturação acadêmica distintos, buscam dar conta precisamente desse compromisso com processos de transformação por parte de coletivos artísticos, de artistas isolados ou de parcerias diversas.

Não que se pretenda aqui lançar de novo a discussão sobre se a arte possa ou não mudar o destino, mas verificar que existem projetos políticos que recorrem a dimensões estéticas para os seus protestos e manifestos ou propostas artísticas que reivindicam uma dimensão e uma agência política particularmente significativa. Este foi um dos dois eixos aqui explorados neste dossiê e que sintetizamos no texto da chamada para artigos da seguinte forma: na tentativa de problematizar e costurar campos tradicionalmente entendidos como arte e política, com especial atenção para as questões que envolvem o corpo e o espaço político naquilo que tem sido pensado como as poéticas e as políticas da rua.

Por outro lado, há hoje instigantes desafios metodológicos e de criatividade, decorrentes, aliás, de uma conscientização política da atividade científica - quer afirmemos ou neguemos a imbricação entre política e academia - e de uma inquietação reflexiva referente aos modos de fazer ciência, que importa aqui trazer à discussão. A maioria dos textos aqui apresentados trazem reflexões, discussões e reformulações dos princípios genéricos de fazer ciência.

Assim, em alguns textos, torna-se visível a reflexividade e permeabilidade dos discursos literários e acadêmicos - fato, aliás, nem por isso novo se pensarmos, nos idos dos anos de 1980, os contributos pós-modernos de um conjunto de autores epitomizado na consagrada obra Writing Culture. Em outros, os diálogos entre a escrita e práticas artísticas e acadêmicas são colocados em planos semelhantes. 
Em alguns casos, são as metodologias colaborativas que são evocadas, trazendo para a escrita antropológica conceitos nativos e formas colaborativas de pensar os temas de pesquisa. Em outros ainda são formas de textualidade artística que invadem, literalmente, o texto etnográfico. Certas contribuições, por outro lado, mantendo uma certa tradição acadêmica de apresentação dos "produtos" de investigação, procuram destabilizar o cenário teórico da disciplina a partir de uma certa indisciplina na conformação do referencial analítico com que trabalham.

Desta forma, o segundo eixo deste dossiê buscou explicitar também as articulações entre novos modos de fazer etnográfico, libertando-se da concepção da antropologia como disciplina de palavras. Aqui, claramente apostamos em textos que exploram imagens e que pensam imagens e sonoridades, em filmes e em coletivos de produção fílmica numa aposta, sempre aberta, das possibilidades de renovação do que, para nós, antropólogos, é fazer antropologia.

Desejamos que tenham uma excelente fruição na leitura deste volume!

PAULO RAPOSO é antropólogo, professor o Departamento de Antropologia do Instituto Universitário de Lisboa (ISCTE-IUL) e foi Professor Visitante da UFSC e da UFF, no Brasil. É investigador e Vice-Presidente do Centro em Rede de Investigação em Antropologia (CRIA). Colabora com diversas estruturas e coletivos artísticos e fez curadoria de vários eventos que pensam a relação entre arte e política em cruzamentos transdisciplinares. A sua investigação incide sobre performances culturais e estéticas, movimentos sociais, artivismo, património imaterial, espaço público e foi reunida em diversas publicações nacionais e internacionais. Coordena um grupo informal de pesquisa sobre Performance, Arte e Decolonialidades e é membro do Núcleo de Antropologia Visual e da Arte no CRIA. E-mail: pjp.raposo@gmail.com

VITOR GRUNVALD é professor do Departamento de Antropologia da Universidade Federal do Rio Grande do Sul (UFRGS) onde coordena o Núcleo de Antropologia Visual (Navisual). Atua também como coordenador do Grupo de Reconhecimento em Universos Artísticos e Audiovisuais (GRUA-IFCS/UFRJ) e participa dos seguintes núcleos de pesquisa ligados à Universidade de São Paulo (USP): Grupo de Antropologia Visual (GRAVI), Núcleo de Antropologia, Performance e Drama (NAPEDRA), Pesquisas em Antropologia Musical (PAM) e Núcleo de Estudos sobre Marcadores Sociais da Diferença (NUMAS). E-mail:vgrunvald@gmail.com

Contribuição de autoria. Paulo Raposo e Vitor Grunvald: concepção, coleta de dados e análise de dados, elaboração do manuscrito, redação, discussão de resultados. 